\title{
El burnout del profesional: ¿cómo evolucionará en tiempos de crisis?
} The professional's burnout: how will it evolve in times of crisis?

\author{
A. Castel Riu
}

\author{
Psicólogo Clínico. Unidad de Dolor. Hospital Universitari Joan XXIII. Tarragona. Grup Multidisciplinari \\ d'Investigació en Dolor. Institut d'Investigació Sanitària Pere Virgili. Tarragona, España
}

La frecuente exposición al padecimiento de las personas está asociada a una mayor presencia de distrés emocional en los profesionales del ámbito clínico. La aparición de la pandemia COVID-19 (SARS-CoV-2) ha tenido un gran impacto en el sistema sanitario y en los profesionales que trabajan en él.

Esta nueva situación ha generado cambios contextuales que han podido agravar situaciones ya preexistentes, contribuyendo al aumento de la fatiga física y mental, de la ansiedad, del estrés y del agotamiento de los profesionales sanitarios. Concretamente, y vinculados a la aparición de la pandemia, recientes estudios han identificado que entre los factores que pueden incidir en la salud mental de los profesionales sanitarios se encuentran: 1) los recursos limitados en los hospitales, 2) la exposición al virus como amenaza añadida, 3] los turnos más largos, 4) la interrupción de los patrones de sueño, 5) el equilibrio de la vida laboral-vida personal, 6) la presencia de mayores dilemas con respecto a los deberes hacia el paciente versus el miedo a la exposición de los miembros de la familia, 7] la desatención de las necesidades personales y familiares por la mayor carga de trabajo, y 8) la falta de comunicación e información actualizada (1).

Por otra parte, la pandemia COVID-19 [SARS-CoV-2] también ha incidido en los pacientes con dolor crónico. Concretamente, se han impuesto grandes limitaciones que han afectado al uso de los espacios públicos, al acceso al trabajo, a la educación o a las instalaciones recreativas, pero también ha limitado el acceso a determinados servicios sanitarios, vitales pero no urgentes, como los que están incluidos en la cartera de servicios, de alta calidad y especializados, que ofrecen la unidades de tratamiento del dolor [ㄹ]

Por tanto, este nuevo contexto introduce retos al profesional que ha de tratar al paciente con dolor. Puede aumentar la complejidad psicosocial del propio paciente y el proceso de evaluación y tratamiento se torna más complejo, requiriendo un mayor esfuerzo de ajuste y adaptación.
Entre los profesionales que han de cuidar de la salud, el síndrome de burnout [o desgaste profesional) es un sindrome relativamente frecuente. Fue inicialmente conceptualizado por el psiquiatra $H$. J. Freudenberger a mediados de la década de los setenta, pero no fue hasta 1982 que Marlach y Jackson operativizaron este concepto con la creación del Maslach Burnout Inventory (MBI). Desde su creación, el MBl es el instrumento estandarizado más importante en la determinación del burnout.

Maslach y cols. (프) consideran el burnout como una respuesta prolongada a estresores crónicos a nivel personal y relacional en el trabajo, determinado a partir de las dimensiones conocidas como agotamiento, cinismo e ineficacia profesional. Por tanto, el burnout tiene un carácter tridimensional que afecta a nivel personal lagotamiento: sensación de estar exhausto emocionalmente por las demandas del trabajo), a nivel social (cinismo o despersonalización: actitud distante y fría ante el trabajo, las personas objeto del mismo, así como los compañeros/as de trabajo] y por último, a nivel profesional (ineficacia profesional: sensación de ineficacia, de no hacer adecuadamente las tareas y ser incompetente en el trabajo]. Estos componentes aparecen de forma insidiosa, cíclica y pueden repetirse a largo del tiempo, de modo que una persona puede experimentar los tres componentes varias veces en diferentes épocas de su vida y en el mismo o en otro trabajo.

Aunque el burnout ha sido objeto de amplia atención en el ámbito de la salud, son muy pocos los trabajos que hayan tenido como objeto a los profesionales que trabajan en unidades de dolor. En nuestro país, Riquelme y cols. (4) publicaron en el año 2018 un interesante trabajo en el que estudiaron la prevalencia de burnout entre médicos de diferentes departamentos que abordaban el tratamiento del dolor. Entre ellos había profesionales de unidades de dolor, pero también de otros servicios, como traumatología, rehabilitación, oncología, reumatología o atención primaria. En su estudio encontraron que el 22,6 \% de los participantes pre- 
sentaba agotamiento, el 22,3 \% despersonalización y el 24,9\% sensación de ineficacia profesional.

Ya centrados exclusivamente en profesionales sanitarios vinculados a unidades de dolor, existe un trabajo de reciente aparición realizado por Ashton-James y cols. (드) que examinó la prevalencia del burnout entre los profesionales vinculados a unidades multidisciplinares. La muestra de estudio estuvo formada por médicos, psicólogos, fisioterapeutas, personal de enfermería y terapeutas ocupacionales, entre otros. Aunque no abordó la complejidad surgida a raíz de la pandemia del COVID-19 [SARS-CoV-2], dado que el trabajo de campo es anterior a la eclosión de la misma, sí ayuda a comprender el peso de determinadas variables en la aparición del burnout. Asimismo, sugiere posibles acciones a emprender para mitigar su aparición y permite comprender la importancia de estudiar esta problemática en el complejo contexto actual.

La muestra estuvo formada por 178 profesionales [33,5 \% de medicina, 17,5\% de psicología, 13,1\% de fisioterapia y 13,1\% de enfermería, como los de mayor representación] pertenecientes a 58 unidades multidisciplinarias del dolor. Además de evaluar el síndrome de burnout con el $\mathrm{MBI}$, los investigadores evaluaron otros aspectos. Concretamente, la confianza del profesional en el manejo de las emociones del paciente y la confianza en el manejo de sus propias emociones. Asimismo, se incluyeron tres preguntas abiertas en las que se valoraban las ventajas y desventajas de trabajar en una unidad multidisciplinaria en relación con el estrés y el bienestar.

Los resultados mostraron que el 21,6 \% de los participantes presentaba agotamiento emocional, el 14,2 \% altos niveles de despersonalización y el $18,8 \%$ sensación de ineficacia profesional. Para determinar posibles factores de predicción del síndrome de burnout se introdujeron las siguientes variables: género, rol profesional, años de experiencia, titularidad pública vs. privada del centro de trabajo, área geográfica de la unidad, así como confianza en el manejo de las propias emociones y confianza en el manejo de las emociones de los pacientes. De todas estas variables, solo dos fueron significativas. La falta de confianza en el manejo de las propias emociones predijo el agotamiento emocional y la falta de confianza en el manejo de las emociones de los pacientes predijo la despersonalización. El agotamiento emocional y la despersonalización estuvieron positivamente correlacionados, en tanto que el sentimiento de ineficacia profesional estuvo inversamente correlacionado con las dos variables anteriores.

El análisis de tipo cualitativo permitió valorar aspectos organizativos, entre otros, sobre la complejidad de los pacientes o sobre la interacción con los compañeros de unidad. En relación con los aspectos organiza- tivos, la falta de recursos y la carga de trabajo aparecieron como factores de estrés para la cuarta parte de los entrevistados. La complejidad de los pacientes era tanto fuente de bienestar como de malestar. En concreto, algunos profesionales valoraban que la complejidad psicosocial del paciente podía representar un reto profesional estimulante y una oportunidad para la creatividad y la innovación. Por el contrario, otros remarcaban la frustración ante esas mismas dificultades. Mayor acuerdo existía en valorar la consecución de resultados terapéuticos como una importante fuente de bienestar. Finalmente, la relación con los colegas, aunque podía ser también fuente de malestar, era considerada por una mayoría como fuente de bienestar emocional, tanto por el apoyo de los colegas como por la riqueza del equipo multidisciplinar.

En conclusión, los hallazgos de este trabajo apuntan sobre la importancia de proporcionar a los clínicos capacitación para mejorar su confianza en el manejo de las emociones, tanto de las propias como de las de los pacientes. Asimismo, subrayan los beneficios de trabajar en equipos cohesionados. El actual contexto de la pandemia COVID-19 (SARS-CoV-2) añade complejidad a la labor del profesional y, tal vez, añada otras variables diferentes a las aquí reseñadas.

\section{BIBLIOGRAFÍA}

1. Raudenská J, Steinerová V, Javurková A, Urits I, Kaye AD, Viswanath 0 , et al. Occupational burnout syndrome and posttraumàtic stress among healthcare professionals during the novel coronavirus disease 2019 (COVID-19) pandèmic. Best Pract Res Clin Anaesthesiol. 2020;34(3):553-60. DOI: 10.1016/j.bpa.2020.07.008.

2. Cohen SP, Baber ZP, Buvanendran A, McLean BC, Chen Y, Hooten $M$, et al. Pain management best practices from multispecialty organizations during the COVID-19 pandemic and public health crises. Pain Med. 2020;21(7):1331-46. DOI: 10.1093/pm/pnaa127.

3. Maslach C, Schaufely WB, Leiter MP. Job burnout. Annu Rev Psychol. 2001;52:397-422. D0I: 10.1146/annurev. psych.52.1.397.

4. Riquelme I, Chacón Jl, Gándara AV, Muro I, Traseira S, Monsalve $\mathrm{V}$, et al. Prevalence of burnout among pain medicine physicians and its potential effect upon clinical outcomes in patients with oncologic pain or chronic pain of nononcologic origin. Pain Med. 2018;19(12):2398-407. DOI: 10.1093/ $\mathrm{pm} / \mathrm{pn} \times 335$.

5. Ashton-James CE, McNeilage AG, Avery NS, Robson LHE, Costa D. Prevalence and predictors of burnout symptoms in multidisciplinary pain clinics: a mixed-methods study. Pain. 2021;162(2):503-13. DOI: 10.1097/j. pain. 0000000000002042 